\title{
An experimental study of detection limits and corresponding doses of IRSN in vivo monitoring vehicles in the case of post-accident scenarios
}

\author{
D. Broggio ${ }^{1 \star}$, É. Navarro ${ }^{2}$, D. Viltard ${ }^{1}$, C. Challeton-de Vathaire ${ }^{1}$, R. Bô ${ }^{1}$, L. Debrose $^{1}$, X. Moya ${ }^{1}$ \\ and D. Franck ${ }^{1}$ \\ 1 IRSN/PRP-HOM/SDI/LEDI, BP 17, 92262 Fontenay-aux-Roses, France. \\ 2 IRSN/PRP-CRI/SESUC/BSPA, BP 17, 92262 Fontenay-aux-Roses, France.
}

Received 18 March 2014 - Accepted 11 June 2014

\begin{abstract}
The measurement performances of in vivo monitoring vehicles were studied considering an increase in the radiological background in areas where the population is not evacuated after a nuclear accident. The study focused on ${ }^{137} \mathrm{Cs}$ and ${ }^{131}$ I Detection Limits (DLs) and corresponding doses, for adults and one-year-old children. These DLs for ground contamination were obtained experimentally using a grid of point sources. Then, the DLs and doses were calculated using the experimental data and a safety factor for two accident scenarios. For these scenarios the ${ }^{137} \mathrm{Cs} \mathrm{DL}$ corresponds to a committed effective dose of $0.02 \mathrm{mSv}$. The ${ }^{131} \mathrm{I} \mathrm{DL}$ corresponds to committed equivalent thyroid doses of $3 \mathrm{mSv}$ (adult) and $30 \mathrm{mSv}$ (one-year-old child). To guarantee a $45 \mathrm{mSv}$ thyroid equivalent dose assessment for the child the surface activity of ${ }^{131} \mathrm{I}+{ }^{132} \mathrm{I}+{ }^{133} \mathrm{I}$ should be below $1.6 \mathrm{MBq} / \mathrm{m}^{2}$. This study shows that the vehicles can operate in a contaminated area where the population is not evacuated. However, in such a case, the contamination level outside and inside the vehicle should be kept stable to guarantee efficient body counting.
\end{abstract}

Keywords: in vivo monitoring / detection limit / post-accident management / ground contamination

\section{Introduction}

In vivo counting aims at assessing the body content of radionuclides by direct external measurements; it can be performed in routine monitoring programmes or in emergency situations. The assessed retained activity enables the calculation of the committed effective dose and hence the potential risk resulting from the incorporation of radionuclides (ICRP, 1997).

Several mobile laboratories have been developed all over the world (Boddy, 1967; Hille et al., 2000; Bondarkov et al., 2001; Castagnet et al., 2007; Dantas et al., 2010). The French Institute for Radiological protection and Nuclear Safety (IRSN) has updated the former SCPRI fleet of Mobile Units (MUs) dedicated to emergency situations (Pellerin and Moroni, 1969). In the case of a nuclear incident it has been recently suggested (ASN, 2012) that the MUs could be located in areas where the population is not evacuated but where there is a significant increase in the radioactivity.

Thus, the measurement performances of the MUs were studied under an increase in the radiological background. For this purpose, the response of in vivo monitoring detectors was studied for experimentally simulated ground surface contamination. From the experimental results the detection limits

\footnotetext{
* david.broggio@irsn.fr
}

for ${ }^{137} \mathrm{Cs}$ and ${ }^{131} \mathrm{I}$ were deduced for single radionuclide ground surface contamination and two typical accident scenarios. The detection limits were used to estimate the corresponding minimum committed effective dose $\left({ }^{137} \mathrm{Cs}\right)$ and thyroid equivalent dose $\left({ }^{131} \mathrm{I}\right)$ for an adult and a one-year-old child. Finally, a constraint was given in terms of iodine isotope surface concentration to guarantee the assessment of a thyroid dose of $45 \mathrm{mSv}$ to the one-year-old child.

\section{Material and methods}

\subsection{Mobile units and detectors}

The fleet of IRSN MUs has been presented elsewhere (Franck et al., 2012); only details relevant to this study are recalled here. The fleet consists of four "light" vehicles and four bigger air transportable vehicles. In both vehicle types, each exam chair allows simultaneous detection of the thyroid and whole-body content of radionuclides with lead-shielded $\mathrm{NaI}(\mathrm{Tl})$ scintillators. The thyroid detector is calibrated with a thyroid phantom (ICRU, 1992) and the whole-body detector with an anthropomorphic phantom (Kovtun et al., 2000). During in vivo monitoring spectra are displayed and the Region of 

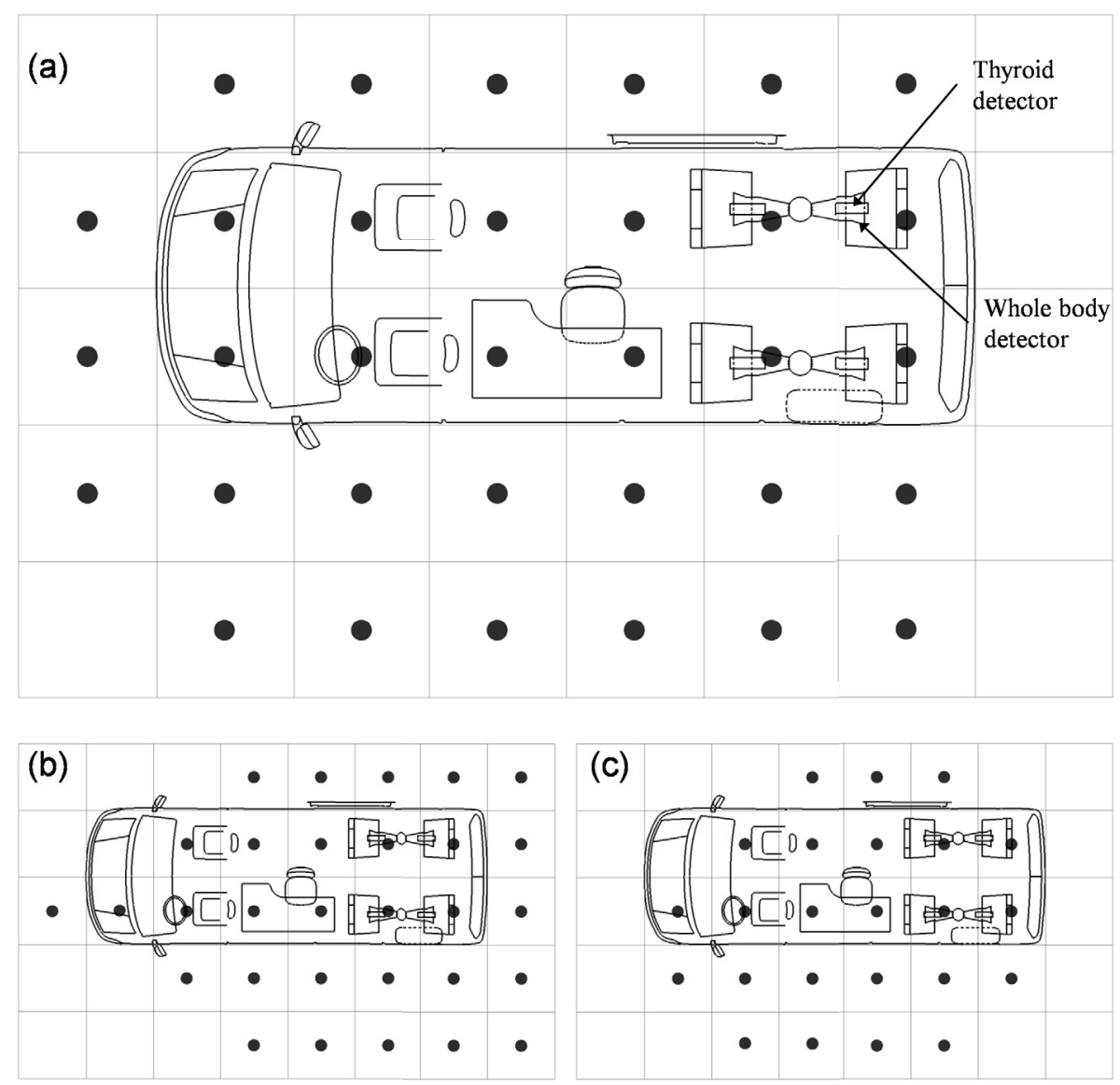

Fig. 1. Locations of point sources around and under the vehicle: (a) ${ }^{60} \mathrm{Co}$, (b) ${ }^{137} \mathrm{Cs}$, (c) ${ }^{133} \mathrm{Ba}$; the drawings are to scale.

Interest (RI) can be selected to record the number of counts in the photoelectric peak of the monitored radionuclides. Dedicated software has been developed to record the number of counts in RIs, generate reports, and assist trained but nonexpert users.

The two detectors of one exam chair of a "light" vehicle were used; the results obtained could be extended to the other vehicles, at least to fix orders of magnitude. The DL is studied for ${ }^{137} \mathrm{Cs}$ (whole-body detector) and for ${ }^{131} \mathrm{I}$ (thyroid detector).

\subsection{Detection limits considering ground surface contamination by a single radionuclide}

\subsubsection{Theory and general experimental idea}

The DL depends on the background counts per unit energy in the region of interest ( $B$ in counts $/ \mathrm{keV})$, the detector energy resolution $(R$ in $\mathrm{keV})$, the counting time ( $t$ in seconds) and the detection efficiency ( $\varepsilon$ in counts/s/Bq) (GTN5, 1989):

$$
D L=8.8 \frac{\sqrt{R B}}{\varepsilon t} .
$$

In a contaminated area only $B$ changes; for a fixed counting time the increase in DL is thus:

$$
D L_{c}=D L_{0} \sqrt{\frac{B_{c}}{B_{0}}}=D L_{0} \sqrt{k A_{s}} .
$$

$D L_{0 / c}$ stands, respectively, for the DL in normal operation conditions and in the contaminated area (idem for $B_{0 / c}$ ), and $A_{s}$ for the ground surface activity of contaminants $\left(\mathrm{MBq} / \mathrm{m}^{2}\right) . B_{0}$ and $D L_{0}$ are known from the commissioning of the MUs. The background counts are naturally proportional to the surface activity and part of this work consists of finding the $k$ coefficient experimentally. If the background contamination is greater than in normal operation conditions $\left(\mathrm{B}_{\mathrm{c}} \gg \mathrm{B}_{0}\right)$ then $\mathrm{LD}_{\mathrm{c}} \gg \mathrm{LD}_{0}$; equation (2) is thus valid for $\mathrm{A}_{\mathrm{s}}>1 / k$, otherwise we will have $\mathrm{LD}_{\mathrm{c}}<\mathrm{LD}_{0}$.

With a large radioactive surface the $k$ coefficient could be obtained directly by measuring the number of counts in a RI. Since this experimental could not be achieved it was simulated using point sources located around and under the MU, using a drawn grid of $1 \mathrm{~m} \times 1 \mathrm{~m}$ squares as shown in Figure 1 .

\subsubsection{Validation of the surface contamination approximation}

A priori it is not guaranteed that a single point source in the centre of a $1 \mathrm{~m} \times 1 \mathrm{~m}$ square will induce the same counts as the equivalent surface activity. To test this hypothesis the grid was subdivided into $25 \mathrm{~cm} \times 25 \mathrm{~cm}$ squares at locations giving the highest count rates and new source configurations were defined on the sub-grids. For these experiments ${ }^{137} \mathrm{Cs}$ was used. For the sub-grid configurations, the average (over new source positions) of counts was compared with the counts obtained with a single source. Thirteen configurations were tested. 


\subsubsection{Final protocol}

After studying the validity of the surface contamination approximation, high activity point sources were used in three separate experiments: ${ }^{60} \mathrm{Co}(1.37 \mathrm{MBq}),{ }^{137} \mathrm{Cs}(6.62 \mathrm{MBq})$ and ${ }^{133} \mathrm{Ba}(6 \mathrm{MBq})$. All experiments and calculations are hereafter carried out for a counting time of $10 \mathrm{~min}$, following the protocol for emergency measurements. The RIs for ${ }^{137} \mathrm{Cs}$ and ${ }^{131} \mathrm{I}$ are $172 \mathrm{keV}$ and $55 \mathrm{keV}$ wide, respectively, and since we work with fixed RIs we use total counts in the RIs rather than counts/keV.

Excess counts (i.e. after subtraction of natural background counts) in ${ }^{137} \mathrm{Cs}$ and ${ }^{131} \mathrm{I}$ RIs were recorded for each position; the source was placed in a position and then moved to the next. The cumulated number of excess counts was considered, i.e. the sum of counts for all positions. The experiment was stopped when enough positions had been used so that the cumulated number of counts stopped increasing. Indeed, the farther the source from the MU, the less significant its contribution; similarly, in the case of ground contamination, the farthest portions of the surface will contribute less than the closest. Finally, when convergence of the number of counts $\left(B_{c}\right)$ was obtained, the $k$ coefficient was calculated as follows:

$$
k=\frac{B_{c}}{B_{0} A_{s}},
$$

where the surface activity is simply the source activity used for the experiment divided by $1 \mathrm{~m}^{2}$.

One thus obtains, according to equation (2), the variation of ${ }^{137} \mathrm{Cs}$ and ${ }^{131} \mathrm{I} \mathrm{DL}$ as a function of the ground surface activity in ${ }^{60} \mathrm{Co},{ }^{137} \mathrm{Cs}$ and ${ }^{133} \mathrm{Ba}$.

It can be noted that ${ }^{60} \mathrm{Co}$ induces counts in ${ }^{137} \mathrm{Cs}$ and ${ }^{131} \mathrm{I}$ RIs due to the scattered radiation, but ${ }^{133} \mathrm{Ba}$ induces counts in the ${ }^{131} \mathrm{I}$ RI by a photoelectric effect (here ${ }^{133} \mathrm{Ba}$ is used as a ${ }^{131} \mathrm{I}$ surrogate). Similarly, in the case of complex ground contamination, the monitored radionuclides will directly interfere by a photoelectric effect, while others will indirectly interfere after scattering.

\subsection{Detection limits considering ground surface contamination by several radionuclides}

A complex mixture of radionuclides, as expected after a nuclear accident, cannot be experimentally simulated, but the counts it induces in RIs can be approximated using the experimental data. For this purpose ${ }^{60} \mathrm{Co},{ }^{137} \mathrm{Cs}$ and ${ }^{133} \mathrm{Ba}$ are considered as surrogates of other radionuclides. More precisely, for a radionuclide ${ }^{i} X$ emitting gamma rays of energy $E_{i j}$, the rays are considered to induce background counts proportional to the surrogate radionuclide whose main gamma line is the closest to $E_{i j}$. The surrogate gamma lines have the following energy: $356 \mathrm{keV}\left(E_{1}\right), 662 \mathrm{keV}\left(E_{2}\right)$ and $1173 \mathrm{keV}\left(E_{3}\right)$. The proportionality coefficient takes into account the emission intensities of surrogate and contaminant gamma lines.

From the experimental data, the counts in the ${ }^{131} \mathrm{I}$ RI due to $1 \mathrm{MBq} / \mathrm{m}^{2}$ of ${ }^{137} \mathrm{Cs}$ are known; let us note $B_{s}\left(I,{ }^{137} \mathrm{Cs}\right)$ as this quantity. Similarly, $B_{s}\left(C s,{ }^{60} C o\right)$ is the number of counts in the ${ }^{137} \mathrm{Cs}$ RI due to $1 \mathrm{MBq} / \mathrm{m}^{2}$ of ${ }^{60} \mathrm{Co}$.
Let us also define $Y_{i}\left(E_{i j}\right)=\sum_{j} y_{i}\left(E_{i j}\right)$, with $y_{i}\left(E_{i j}\right)$ the $j$ th gamma emission intensity at energy $E_{i j}$ of the radionuclide ${ }^{i} X$; and let us note $y_{t o t}\left({ }^{i} X\right)$ the sum of the gamma ray emission intensities of ${ }^{i} X$.

In the ${ }^{137} \mathrm{Cs} \mathrm{RI}$ the number of counts induced by the surface activities $A_{s}\left({ }^{i} X\right)$ can be written:

$$
\begin{aligned}
B_{c}\left({ }^{137} C s\right)= & B_{s}\left(C s,{ }^{137} C s\right) A_{s}\left({ }^{137} C s\right) \\
& +\frac{B_{s}\left(C s,{ }^{137} C s\right)}{y_{t o t}\left({ }^{137} C s\right)} \sum_{E_{i j}>E_{2}}^{E_{i j}<E_{3}} Y_{i}\left(E_{i j}\right) A_{s}\left({ }^{i} X\right) \\
& +\frac{B_{s}\left(C s,{ }^{60} C o\right)}{y_{t o t}\left({ }^{60} C o\right)} \sum_{E_{i j} \geqslant E_{3}} Y_{i}\left(E_{i j}\right) A_{s}\left({ }^{i} X\right) .
\end{aligned}
$$

In equation (4) the first term on the right-hand side is the experimentally known contribution. The other terms only take into account gamma rays with energy greater than $662 \mathrm{keV}$. For example, let us consider that we have a radionuclide emitting a single gamma ray with energy between $\mathrm{E}_{2}$ and $\mathrm{E}_{3} . Y_{i}\left(E_{i j}\right)$ thus resumes the emission intensity of this gamma line; multiplied by $A_{s}\left({ }^{i} X\right)$ it gives the photon flux per unit area, and multiplied by $B_{s}\left(C s,{ }^{137} C s\right)$ it gives the counts in the ${ }^{137} \mathrm{Cs}$ RI as if this radionuclide had the same surface activity as ${ }^{137} \mathrm{Cs}$. It is necessary to divide by $y_{t o t}\left({ }^{137} \mathrm{Cs}\right)$ since $B_{s}\left(C s,{ }^{137} \mathrm{Cs}\right)$ are the counts induced by $1 \mathrm{MBq} / \mathrm{m}^{2}$ of ${ }^{137} \mathrm{Cs}$ and not by photon $/ \mathrm{m}^{2}$. Similarly, one can check that if ${ }^{60} \mathrm{Co}$ is the only contaminant the relation gives the experimentally obtained contribution, i.e. $B_{s}\left(C s,{ }^{60} \mathrm{Co}\right) \mu A_{s}\left({ }^{60} \mathrm{Co}\right)$.

To calculate the number of counts in the ${ }^{131}$ I RI we need to take into account lower energy contributions:

$$
\begin{aligned}
B_{c}\left({ }^{131} I\right)= & B_{s}\left(I,{ }^{131} I\right) A_{s}(131 I)+B_{s}\left(I,{ }^{137} C s\right) A_{s}\left({ }^{137} C s\right) \\
& +\frac{B_{s}\left(I,{ }^{133} B a\right)}{y_{>}\left({ }^{133} B a\right)} \sum_{E_{i j}>E_{1}}^{E_{i j}<E_{2}} Y_{i}\left(E_{i j}\right) A_{s}\left({ }^{i} X\right) \\
& +\frac{B_{s}\left(I,{ }^{137} C s\right)}{y_{\text {tot }}\left({ }^{137} C s\right)} \sum_{E_{i j} \geqslant E_{2}}^{E_{i j}<E_{3}} Y_{i}\left(E_{i j}\right) A_{s}\left({ }^{i} X\right) \\
& +\frac{B_{s}\left(I,{ }^{60} C o\right)}{y_{\text {tot }}\left({ }^{60} C o\right)} \sum_{E_{i j} \geqslant E_{3}} Y_{i}\left(E_{i j}\right) A_{s}\left({ }^{i} X\right) .
\end{aligned}
$$

In equation (5) we have $B_{s}\left(I,{ }^{131} I\right)$; in fact, only $B_{s}\left(I,{ }^{133} B a\right)$ is known and they are related as follows:

$$
B_{s}\left(I,{ }^{131} I\right)=\frac{0.91}{0.71} B_{s}\left(I,{ }^{133} B a\right)
$$

where the numerator is the sum of the emission intensities of ${ }^{131}$ I gamma rays with energy greater than $365 \mathrm{keV}$ and the denominator the sum of the emission intensities of ${ }^{133} \mathrm{Ba}$ gamma rays with energy greater than $356 \mathrm{keV}$. This last is noted $y_{>}\left({ }^{133} \mathrm{Ba}\right)$ in the third term of equation (5).

Once the counts in the RIs of interest are calculated, equation (2) is applied to obtain the DLs.

\subsection{Accident scenarios and radionuclide spectra}

Two typical accident scenarios leading to radioactive release were considered: a Steam Generator Tube Rupture 


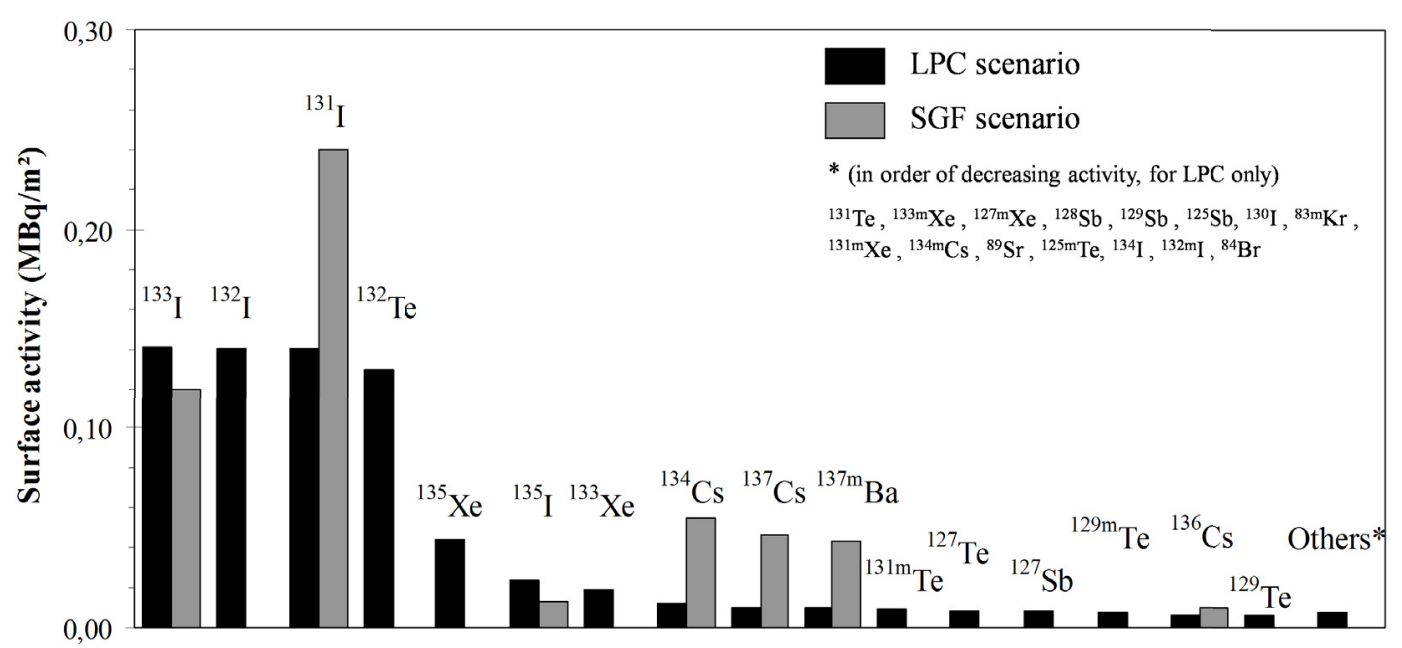

Fig. 2. Radionuclide composition of the ground surface contamination for the LPC and SGTR scenarios, $24 \mathrm{~h}$ after the release and $5 \mathrm{~km}$ from the release point.

(SGTR) and a Loss of Primary Coolant with core meltdown without vessel rupture (LPC). The total released activity was $2.1 \times 10^{16} \mathrm{~Bq}(\mathrm{LPC})$ and $3.1 \times 10^{13} \mathrm{~Bq}$ (SGTR). The durations of the release were $1 \mathrm{~h}$ (SGTR) and $24 \mathrm{~h}$ (LPC).

For each scenario the ground contamination and dose maps were calculated by the Technical Crisis Centre of the IRSN. A location $5 \mathrm{~km}$ from the release point, where the predicted doses were low enough to avoid evacuation of the population but high enough to require restriction of drinking and eating (ASN, 2012) was selected; such areas are called Population Protection Areas (PPAs). Inside the PPA the location $5 \mathrm{~km}$ from the release point corresponded to the highest ground contamination. At this location the surface activities were obtained at $24 \mathrm{~h}, 48 \mathrm{~h}, 72 \mathrm{~h}$ and 7 days. The distribution of surface activities at $24 \mathrm{~h}$ is shown in Figure 2.

\subsection{Dose calculation}

The radionuclide composition of both scenarios was taken into account at the different times and DLs for ${ }^{137} \mathrm{Cs}$ and ${ }^{131} \mathrm{I}$ calculated as described in previous sections. DLs correspond to the minimal detectable retained activity and hence to a minimum assessable dose. The dose calculation was performed according to the biokinetic models of the ICRP (1990, 1993, 1994) using the DCAL software (Eckerman et al., 2001). Briefly, the DL is used to calculate the corresponding intake. From the intake the committed effective dose due to ${ }^{137} \mathrm{Cs}$ and the thyroid equivalent dose due to ${ }^{131} \mathrm{I}$ are obtained. Measurements are considered at $24 \mathrm{~h}, 48 \mathrm{~h}, 72 \mathrm{~h}$ and 7 days following the release. Calculations were performed for an adult and a one-year-old child, considering an acute inhalation intake.

\section{Results and discussion}

\subsection{Validation of the surface contamination approximation and safety factor}

Figure 3 shows the relative difference in counts when one or several sources are used to simulate ground surface contamination; a negative difference means that the single source induces less counts than several sources. For both detectors, in most cases, the single source configuration gives an overestimate of counts, as compared with several sources on the subdivided grid. However, in some cases the single source configuration gives an underestimate.

As a consequence, a multiplicative safety factor of 1.3 (roughly corresponding to the worst case) is hereafter applied to the experimental cumulative counts in the RIs. As a consequence, the safety factor for all DLs is 1.14 . The dominance of positive differences shown in Figure 3 tends to prove that the single source approximation gives a conservative estimate of DLs; consequently, application of the safety factor is particularly careful.

\subsection{Detection limit for ground surface contamination by a single radionuclide}

The evolution, with the number of grid points, of cumulative counts in ${ }^{137} \mathrm{Cs}$ and ${ }^{131} \mathrm{I}$ RIs is shown in Figure 4. The counts are normalised with the ground surface activity so that the "saturation value" of the curves is the number of counts due to $1 \mathrm{MBq} / \mathrm{m}^{2}$, as defined in equations (4) and (5). Figure 4 shows the experimental raw data; the safety factor is not taken into account.

As expected, the counts are dominated by locations near the detectors so that a constant value is reached for about 25 grid locations. Nevertheless, the higher the source energy the more points are needed (the curves for ${ }^{60} \mathrm{Co}$ stabilise slowly). For the same surface activity, ${ }^{60} \mathrm{Co}$ induces more events in the ${ }^{137} \mathrm{Cs}$ and ${ }^{131} \mathrm{I}$ RI than ${ }^{137} \mathrm{Cs}$ or ${ }^{133} \mathrm{Ba}$. Even if unexpected, it might be explained by the strong emission intensity and high energy of ${ }^{60} \mathrm{Co}$ gamma rays. For the thyroid detector, however, the events induced by ${ }^{137} \mathrm{Cs}$ are less significant than those induced by ${ }^{133} \mathrm{Ba}$. The whole-body detector, due to its large size, sees more events than the thyroid detector.

From the saturation values and the DLs in normal conditions of use, the DLs as a function of the ground surface 


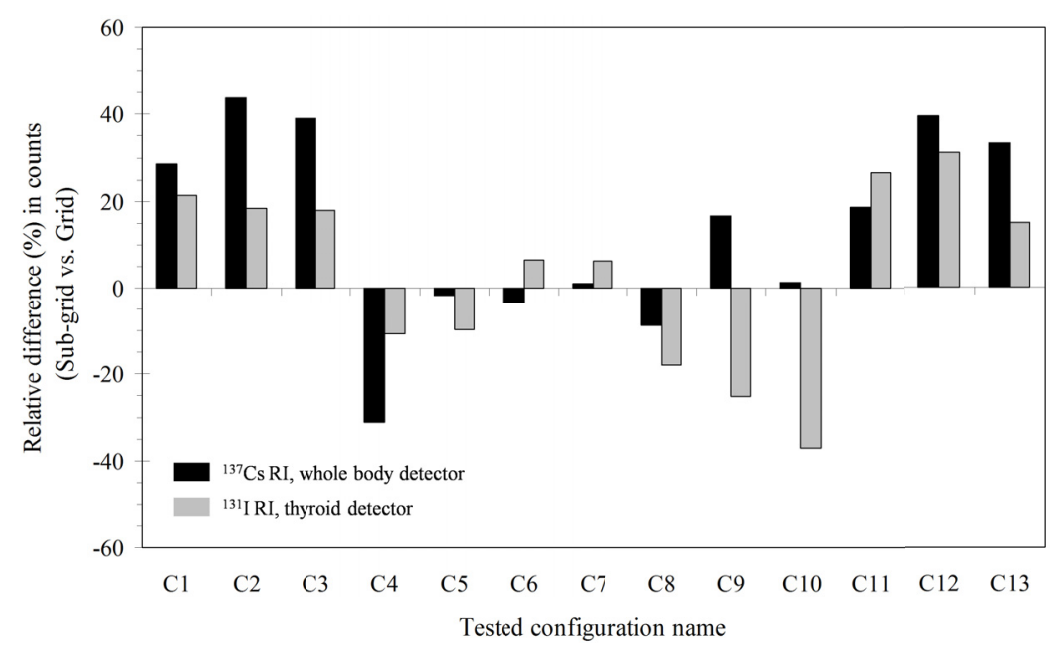

Fig. 3. Relative difference between normalised counts for point sources on the $(1 \mathrm{~m} \times 1 \mathrm{~m})$ grid or on the $(25 \mathrm{~cm} \times 25 \mathrm{~cm}) \mathrm{sub}$-grid.

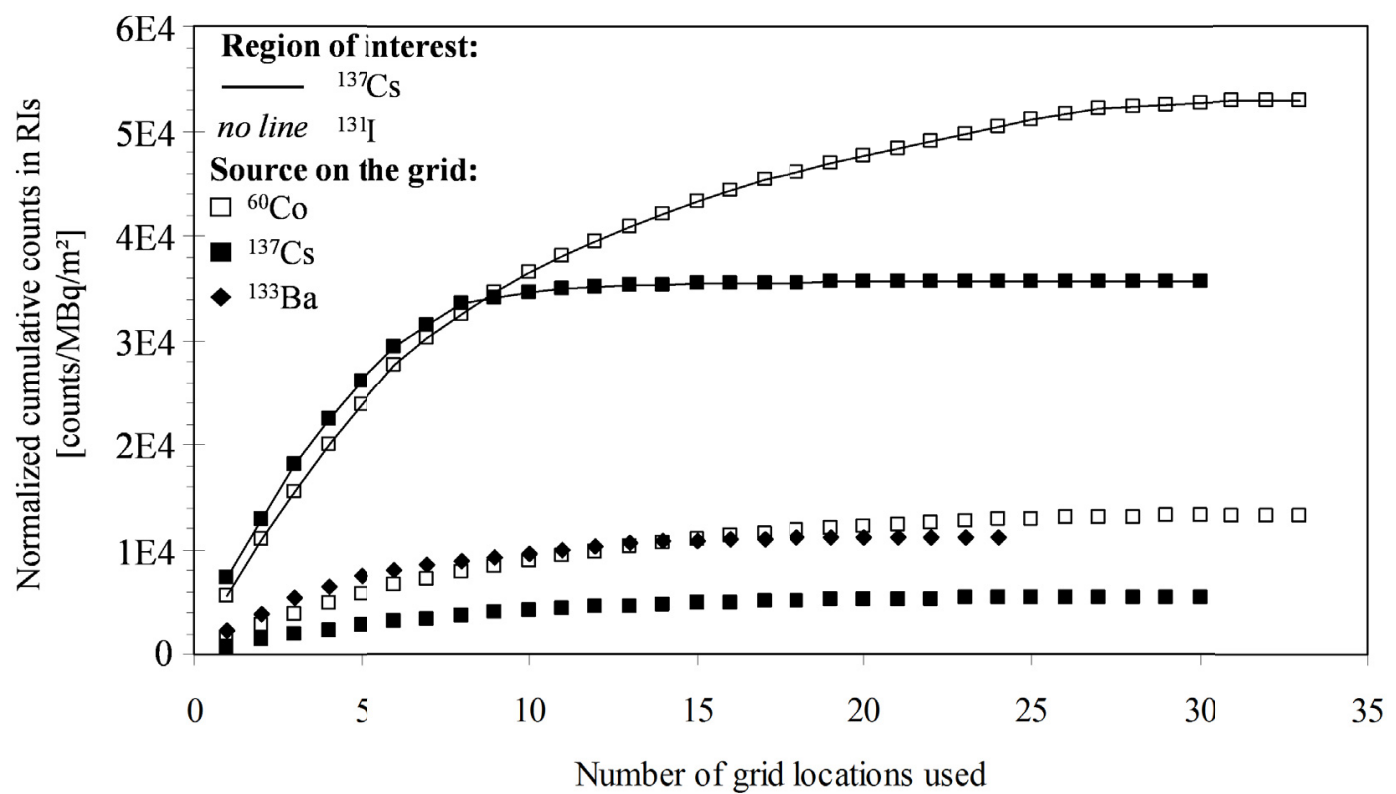

Fig. 4. Variation of the cumulated number of counts, normalised with ground surface activity, in regions of interest with the number of grid locations used.

Table 1. Parameters $\left(k\right.$ and $\left.\mathrm{DL}_{0}\right)$ giving the variation of ${ }^{131} \mathrm{I}$ and ${ }^{137} \mathrm{Cs}$ DLs as a function of the surface activity $\left(\mathrm{DL}=\mathrm{DL}_{0} \sqrt{k A_{s}}\right)$.

\begin{tabular}{lccc}
\hline $\begin{array}{l}\text { Measured } \\
\text { radionuclide }\end{array}$ & $\begin{array}{c}\text { Ground } \\
\text { contaminant }\end{array}$ & DL $_{\mathbf{0}}(\mathbf{B q})$ & $\boldsymbol{k}\left(\mathbf{m}^{2} / \mathbf{M B q}\right)$ \\
\hline \multirow{3}{*}{${ }^{131} \mathrm{I}$} & ${ }^{131} \mathrm{I}$ & & 76 \\
& ${ }^{137} \mathrm{Cs}$ & 237 & 28 \\
& ${ }^{60} \mathrm{Co}$ & & 69 \\
${ }^{137} \mathrm{Cs}$ & ${ }^{137} \mathrm{Cs}$ & 327 & 63 \\
& ${ }^{60} \mathrm{Co}$ & & 93 \\
\hline
\end{tabular}

activity are obtained ( $c f$. Eq. (2)), as summarised in Table 1. In Table 1 the safety factor is taken into account and the ${ }^{131} \mathrm{I}$ DL for ${ }^{131}$ I ground contamination is deduced from the experimental ${ }^{133}$ Ba data ( $c f$. Eq. (6)).

\subsection{Detection limits and corresponding dose for accident scenarios}

Using the surface activity of the scenarios the background in RIs was calculated with equations (4) and (5) and then ${ }^{137} \mathrm{Cs}$ and ${ }^{131} \mathrm{I}$ DLs obtained with equation (2). For the one-year-old child the thyroid counting efficiency was approximated with the adult one. Due to the small size of the child's thyroid the counting efficiency is higher than in the adult case, and the adult DL is thus an overestimate. The corresponding calculated dose (using biokinetic models for the child) is thus a conservative estimate. The same applies for the whole-body efficiency.

The DLs and corresponding doses are reported in Table 2 for the two scenarios and four measurement dates. The first two days the DLs are greater for the LPC scenario than for the SGTR scenario, but it is the contrary at $72 \mathrm{~h}$ and 7 days, which is due to the predominance of short-life radionuclides in the 
Table 2. ${ }^{137} \mathrm{Cs}$ and ${ }^{131} \mathrm{I}$ DLs and corresponding doses for an adult and a one-year-old child, at different measurement times and for the two accident scenarios.

\begin{tabular}{|c|c|c|c|c|c|c|c|c|c|}
\hline & \multirow{2}{*}{ Measurement at } & \multicolumn{2}{|c|}{$24 \mathrm{~h}$} & \multicolumn{2}{|c|}{$48 \mathrm{~h}$} & \multicolumn{2}{|c|}{$72 \mathrm{~h}$} & \multicolumn{2}{|c|}{7 days } \\
\hline & & LPC & SGTR & LPC & SGTR & LPC & SGTR & LPC & SGTR \\
\hline & ${ }^{137} \mathrm{Cs}$ DL (kBq) & 1.9 & 1.2 & 1.6 & 0.9 & 0.4 & 0.9 & 0.4 & 0.9 \\
\hline $\begin{array}{l}\text { Committed } \\
\text { effective dose due }\end{array}$ & $\begin{array}{l}\text { Public member } \\
\text { adult }\end{array}$ & 0.02 & 0.01 & 0.02 & 0.01 & 0.01 & 0.01 & 0.01 & 0.01 \\
\hline to ${ }^{137} \mathrm{Cs}(\mathrm{mSv})$ & One-year-old-child & 0.02 & $\lesssim 0.01$ & $\lesssim 0.02$ & $\lesssim 0.01$ & $\lesssim 0.006$ & $\lesssim 0.01$ & $\lesssim 0.01$ & $\lesssim 0.01$ \\
\hline & ${ }^{131}$ I DL (kBq) & 1.6 & 1.5 & 1.3 & 1.2 & 0.8 & 1.2 & 0.7 & 1.1 \\
\hline $\begin{array}{l}\text { Thyroid } \\
\text { committed equivalent }\end{array}$ & $\begin{array}{l}\text { Public member } \\
\text { adult }\end{array}$ & 2.7 & 2.6 & 2.4 & 2.1 & 1.5 & 2.3 & 1.9 & 3.0 \\
\hline dose (mSv) & One-year-old-child & $\lesssim 22.5$ & $\lesssim 21.3$ & $\lesssim 20.6$ & $\lesssim 18.8$ & $\lesssim 13.8$ & $\lesssim 20.3$ & $\lesssim 19.4$ & $\lesssim 30.1$ \\
\hline
\end{tabular}

SGTR scenario. The DLs for ${ }^{131} \mathrm{I}$ are between 0.7 and $1.6 \mathrm{kBq}$ and between 0.4 and $1.9 \mathrm{kBq}$ for ${ }^{137} \mathrm{Cs}$.

For both scenarios and all measurement dates the committed effective dose due to ${ }^{137} \mathrm{Cs}$ ranged between 0.01 and $0.02 \mathrm{mSv}$ in the adult's and child's cases. These values are much smaller than the $1 \mathrm{mSv}$ annual dose limit for the public; roughly speaking, if the surface activity was multiplied by a factor of 1000 the ${ }^{137}$ Cs DL would still correspond to doses below $1 \mathrm{mSv}$.

For both scenarios, the committed equivalent dose to the thyroid is between 1.5 and $3 \mathrm{mSv}$ in the adult's case, but between 13.8 and $30.1 \mathrm{mSv}$ for the child. The difference between the adult and the child is due to the fact that for a given activity the concentration is higher for the child than for the adult. In the thyroid case, for both scenarios, a measurement at 7 days corresponds to a minimum dose slightly higher than at $72 \mathrm{~h}$ even if the detection limit is slightly better. This is due to iodine elimination that means that similar measured contents correspond to higher intakes when time passes.

For the two studied scenarios the $1 \mathrm{mSv}$ effective dose and $50 \mathrm{mSv}$ equivalent dose to the thyroid can be assessed with the MUs, even for the one-year-old child, assuming a measurement performed 7 days after the release.

\subsection{Constraint for thyroid dose assessment}

The two studied scenarios are just examples and one can speculate how the DLs and corresponding doses are modified for higher activities. From the previous results it is clear that the most problematic case is the thyroid dose for the one-yearold child. For the studied scenarios about $80 \%$ of the background counts in the ${ }^{131}$ I RI come from the iodine isotopes.

The above-mentioned calculations for a measurement at $24 \mathrm{~h}$ were thus restarted with a variable increasing total activity. For both scenarios the thyroid equivalent dose for the child was then plotted as a function of the ground surface activity in ${ }^{131} \mathrm{I}+{ }^{132} \mathrm{I}+{ }^{133} \mathrm{I}$ and the minimum surface activity of iodine isotopes corresponding to $45 \mathrm{mSv}$ was deduced. The $45 \mathrm{mSv}$ value is a careful choice since the dose constraint is in fact $50 \mathrm{mSv}$.

It was found that the surface activity of ${ }^{131} \mathrm{I}+{ }^{132} \mathrm{I}+{ }^{133} \mathrm{I}$ should be below $1.6 \mathrm{Mbq} / \mathrm{m}^{2}$; if not, it is not possible to assess an equivalent dose as low as $45 \mathrm{mSv}$ for the one-year-old child.

\subsection{Discussion}

For the studied scenarios it was shown that the MUs could be used in the Population Protection Area; a constraint was given for iodine isotope surface activity so that one can decide if it is useful or not to use the MUs. This constraint is of practical interest since surface contamination can be measured experimentally. The studied scenarios do not cover all possible cases but a calculation spreadsheet was developed to take into account other scenarios. In the case of accidental release, calculation tools or direct measurement could thus provide the data needed to predict if a location is suitable for the MUs.

In the studied scenarios the maximum ${ }^{131} \mathrm{I}$ and ${ }^{137} \mathrm{Cs}$ surface activities were, respectively, 0.2 and $0.05 \mathrm{MBq} / \mathrm{m}^{2}$. For the early days of the Chernobyl accident, ${ }^{131} \mathrm{I}$ surface activity was reported to be between 4 and $29 \mathrm{MBq} / \mathrm{m}^{2}$ in Ukraine (Talerko, 2005) and between 0.9 and $67 \mathrm{MBq} / \mathrm{m}^{2}$ in Belarus (Straume et al., 2006). For the Fukushima accident the maximum ${ }^{131}$ I daily surface activity reported in (Terada et al., 2012) is around $0.1 \mathrm{MBq} / \mathrm{m}^{2}$. In the early days of the Chernobyl accident the ${ }^{137} \mathrm{Cs}$ activity in the Bryansk region was between 0.01 and $4.3 \mathrm{MBq} / \mathrm{m}^{2}$ and the 2001 values were between 0.009 and $3 \mathrm{MBq} / \mathrm{m}^{2}$ (Ramzaev et al., 2006). For the Fukushima accident the highest daily deposition for ${ }^{137} \mathrm{Cs}$ was around $0.01 \mathrm{MBq} / \mathrm{m}^{2}$ (Terada et al., 2012). The surface activities considered in this study are thus consistent with the reported literature values, except for ${ }^{131} \mathrm{I}$ in the early days of the Chernobyl accident.

Several improvements of this work are possible. First, thyroid and whole-body child phantoms could be used to deduce more reliable estimates of DLs. Second, the air contamination could be taken into account. For this purpose, acquiring experimental data following the method employed here would be very difficult and tedious. Calculating the detector response with Monte Carlo methods was found to be reliable for welldefined experimental situations (Lamart et al., 2009; Lopez et al., 2011; Broggio et al., 2012). However, in the present case a very detailed model of the MUs would be necessary because of the significance of scattered radiation. Third, more accurate dose estimates could be obtained. Indeed, even if only ${ }^{131} \mathrm{I}$ or ${ }^{137} \mathrm{Cs}$ are detected it could be reasonably assumed that other radionuclides have been inhaled too. In this case, an acute description of the air concentration of radionuclides at the time of intake would be necessary. 
Finally, it was shown that the MUs can be positioned where the radiological background is considerably increased. In such a case special attention should be paid to the positioning of the MUs. First, parking them inside a covered site would limit the background changes induced by meteorological conditions and the period between background measurements could be reduced. Thus, the measurement rate of the public would be close to the optimal one. Second, the measured population should wear exam clothes and be controlled for external contamination before in vivo monitoring. If contamination is deposited inside the vehicle, one risks declaring false internal contamination.

\section{Conclusion}

The ${ }^{131} \mathrm{I}$ and ${ }^{137} \mathrm{Cs}$ DLs and corresponding doses were assessed for the IRSN in vivo monitoring vehicles under an increase in the radiological background. For this purpose, ground surface contamination was experimentally simulated with a grid of point sources. Then, two accident scenarios were considered and the DLs and corresponding doses approximated using the available experimental data.

It was found that a committed effective dose due to ${ }^{137} \mathrm{Cs}$ as low as $0.02 \mathrm{mSv}$ can be assessed for an adult and a oneyear-old child. The committed equivalent dose to the thyroid of $3 \mathrm{mSv}$ (adult case) and $30 \mathrm{mSv}$ (one-year-old child) can be assessed for the two studied scenarios. To guarantee a $45 \mathrm{mSv}$ assessment for the child's thyroid the ground surface activity of ${ }^{131} \mathrm{I}+{ }^{132} \mathrm{I}+{ }^{133} \mathrm{I}$ should be below $1.6 \mathrm{MBq} / \mathrm{m}^{2}$. These results were obtained taking into account a safety factor of 1.3 on measured background counts.

The possible limitations and improvement of this work have been discussed. Particularly, it is noted that positioning the vehicle in contaminated areas requires special care of the operation conditions.

\section{References}

ASN (2012) Éléments de doctrine pour la gestion post-accidentelle d'un accident nucléaire - Version finale du 5 octobre 2012. Comité Directeur pour la gestion de la phase post-accidentelle d'un accident nucléaire (CODIRPA). http://www.asn.fr/index. php/Bas-de-page/Sujet-Connexes/Gestionpost-accidentelle/ Comite-directeur-gestion-de-phase-post-accidentelle/Elementsde-doctrinepour-la-gestion-post-accidentelle-d-un-accidentnucleaire-5-octobre-2012.

Boddy K. (1967) A high sensitivity shadow-shield whole body monitor with scanning-bed and tilting chair geometries, incorporated in a mobile laboratory, Br. J. Radiol. 40 (476), 631-637.

Bondarkov M.D., Maksimenko A.M., Gaschak S.P., Zheltonozhsky V.A., Jannik G.T., Farfán E.B. (2001) Method for simultaneous ${ }^{90} \mathrm{Sr}$ and ${ }^{137} \mathrm{Cs}$ in vivo measurements of small animals and other environmental media developed for the conditions of the Chernobyl Exclusion Zone, Health Phys. 101 (4), 383-392.

Broggio D. et al. (2012) Monte Carlo modelling for the in vivo lung monitoring of enriched uranium: Results of an international comparison, Radiat. Meas. 47 (7), 492-500.
Castagnet X., Amabile J.C., Cazoulat A., Lecompte Y., de Carbonnières H., Laroche P. (2007) Diagnosis of internal radionuclide contamination by mobile laboratories, Radiat. Prot. Dosim. 125 (1-4), 469-471.

Dantas B.M., Lucena E.A., Dantas A.L.A., Santos M.S., Julião L.Q.C., Melo D.R., Sousa W.O., Fernandes P.C., Mesquita S.A. (2010) A mobile bioassay laboratory for the assessment of internal doses based on in vivo and in vitro measurements, Health Phys. 99 (4), 449-452.

Eckerman K.F., Leggett R.W., Cristy M., Nelson C.B., Ryman J.C., Sjoreen A.L., Ward R.C. (2001) DCAL: User's Guide to the DCAL System. Oak Ridge National Laboratory Report, ORNL/TM-2001/190.

Franck D., Broggio D., Challeton-de Vathaire C., Moya X., Parre F., Viltard D., Agarande M. (2012) Development of a fleet of intervention mobile unit for radiological accident monitoring of internal contamination. In: Proceedings of IRPA13, May 2012, Glasgow (full paper TS2b.5, available at http://www. irpa13glasgow.com/information/downloads/).

GTN5 (1989) Détermination du seuil et de la limite de détection en spectrométrie gamma. Rapport du Groupe de travail de normalisation No. 5 du Comité d'instrumentation et de radioprotection, CEA-R-5506.

Hille R., Hill P., Heinemann K., Ramzaev V., Barkovski A., Konoplia V., Neth R. (2000) Current development of the human and environmental contamination in the Bryansk-Gomel Spot after the Chernobyl accident, Radiat. Environ. Biophys. 39 (2), 99-109.

ICRP Publication 56 (1990) Age-dependent Doses to Members of the Public from Intake of Radionuclides: Part 1, Ann. ICRP 20 (2).

ICRP Publication 67 (1993) Age-dependent Doses to Members of the Public from Intake of Radionuclides: Part 2 Ingestion Dose Coefficients, Ann. ICRP 23 (3-4).

ICRP Publication 68 (1994) Dose Coefficients for Intakes of Radionuclides by Workers, Ann. ICRP 24 (4).

ICRP Publication 78 (1997) Individual monitoring for internal exposure of workers, Ann. ICRP 27 (3-4).

ICRU Report 48 (1992) Phantoms and Computational Models in Therapy. Diagnosis and Protection, Bethesda, MD, ICRU.

Kovtun A.N., Firsanov V.B., Fominykh V.I., Isaakyan G.A. (2000) Metrological Parameters of the Unified Caibration Whole Body Phantom with Gamma-emiting Radionuclides, Radiat. Prot. Dosim. 89, 239-242.

Lamart S., Blanchardon E., Molokanov A., Kramer G.H., Broggio D., Franck D. (2009) Study of the influence of radionuclide biokinetics on the efficiency of in vivo counting using Monte Carlo simulation, Health Phys. 96 (5), 558-567.

Lopez M.A., Broggio D., Capello K., Cardenas-Mendez E., El-Faramawy N., Franck D., James A.C., Kramer G.H., Lacerenza G., Lynch T.P., Navarro J.F., Navarro T., Perez B., Rühm W., Tolmachev S.Y., Weitzenegger E. (2011) EURADOS intercomparison on measurements and Monte Carlo modelling for the assessment of Americium in a USTUR leg phantom, Radiat. Prot. Dosim. 144 (1-4), 295-299.

Pellerin P., Moroni J.-P. (1969) Le laboratoire mobile de spectrométrie humaine du SCPRI. In: Handling of radiation accidents, Proceedings of a symposium, 19-23 May 1969, Vienna (IAEA, Eds.), pp. 317-325.

Ramzaev V., Yonehara H., Hille R., Barkovsky A., Mishine A., Sahoo S.K., Kurotaki K., Uchiyama M. (2006) Gamma-dose rates from terrestrial and Chernobyl radionuclides inside and 
outside settlements in the Bryansk Region, Russia in 1996-2003, J. Environ. Radioact. 85 (2-3), 205-227.

Straume T., Anspaugh L.R., Marchetti A.A., Voigt G., Minenko V., Gu F., Men P., Trofimik S., Tretyakevich S., Drozdovitch V., Shagalova E., Zhukova O., Germenchuk M., Berlovich S. (2006) Measurement of ${ }^{129} \mathrm{I}$ and ${ }^{137} \mathrm{Cs}$ in soils from Belarus and reconstruction of ${ }^{131} \mathrm{I}$ deposition from the Chernobyl accident, Health Phys. 91 (1), 7-19.
Talerko N. (2005) Reconstruction of ${ }^{131}$ I radioactive contamination in Ukraine caused by the Chernobyl accident using atmospheric transport modelling, J. Environ. Radioact. 84 (3), 343-362.

Terada H., Katata G., Chino M., Nagai H. (2012) Atmospheric discharge and dispersion of radionuclides during the Fukushima Dai-ichi Nuclear Power Plant accident. Part II: Verification of the source term and analysis of regional-scale atmospheric dispersion, J. Environ. Radioact. 112, 141-154.

Cite this article as: D. Broggio, É. Navarro, D. Viltard, C. Challeton-de Vathaire, R. Bô, L. Debrose, X. Moya, D. Franck. An experimental study of detection limits and corresponding doses of IRSN in vivo monitoring vehicles in the case of post-accident scenarios. Radioprotection 49(4), 261-268 (2014). 